\title{
Post-Tonsillectomy Taste Disturbance; An Unusual Complication of Tonsillectomy
}

\author{
${ }^{2}$ Nazmul Hossain Chowdhury, \\ Assistant Professor, \\ Dept. of ENT-HNS, Bangladesh \\ Medical College Hospital \\ ${ }^{5}$ Saif Rahman Khan, \\ Assistant registrar, \\ Dept. ENT, National Institute of ENT
}

\author{
${ }^{1}$ Md. Ashraful Islam, Professor and Head, \\ Otolaryngology-Head \& Neck Surgery, \\ Bangladesh Medical College Hospital \\ ${ }^{3}$ Tareq Mohammad, Assistant \\ Registrar, \\ Dept. of ENT, Bangladesh Medical \\ College Hospital \\ ${ }^{6}$ ASM Lutfur Rahman, \\ Resident Surgeon, \\ Bangladesh Medical College Hospital
}

\author{
${ }^{4}$ Towsif Bin Mamoon, Assistant \\ Registrar, \\ Dept. of ENT, Bangladesh Medical \\ College Hospital \\ ${ }^{7}$ Farid Uddin Milki, \\ Consultant ENT, \\ Bangladesh Medical College Hospital
}

\begin{abstract}
Tonsillectomy is a very common operation to the otolaryngologist and relatively safe in expert hand. Sometimes it bothers the surgeon for its acute and chronic post-operative complications like reactionary hemorrhage, throat pain, referred otalgia, dehydration, velopharyngeal incmpetnce, burns of uvula, soft-tissue injury, dento-mandibular trauma, and respiratory compromise. Although rare, it is often associated with altered taste and temporary or long continued loss of taste sensation. In this article, the authors reported 39 (3.9\%) cases of disturbance of taste sensation among 1000 post-tonsillectomy patients during the period 2015 to 2018 in the Bangladesh medical College Hospital. Age of the patents was ranged in between 20 to 30 year. The study was aimed to find out the possible cause of taste disturbance in the post-tonsillectomy patients and obtain informed written consent prior to tonsillectomy.
\end{abstract}

Keywords:- Post-Tonsillectomy, Taste Disturbance, Complication.

\section{INTRODUCTION}

Tonsillectomy is the most commonly performed operation in otolarynological practice. The surgery is relatively safe but occasionally it gives horrifying troubles to the surgeon for its acute and chronic complications. The complications are mostly hemorrhage, painful throat, difficulty in swallowing, referred otalgia, burns of uvula, soft-tissue injury, dento-mandibular trauma, velopharyngeal incompetence and respiratory compromise. Although rare, it is often associated with altered taste and temporary or long continued loss of taste sensation that is an unusual complication of tonsillectomy. Taste gives pleasure in eating and drinking. It satisfies hunger and carries important physiologic functions which helps to distinguish nutrients from toxins, facilitates digestion; and regulates salt and energy intake ${ }^{1}$. Malnourishment, weight gain or loss happen mostly due to taste disorders. The study was aimed to find out the possible cause of taste disturbance in the post-tonsillectomy patients and obtain informed written consent prior to tonsillectomy.

\section{ANATOMY AND PHYSIOLOGY OF TASTE}

Taste is a special sensation associated with the primary organ tongue that contains taste reception. There are other taste receptors on the tonsillar pillars, palate, epiglottis and upper esophagus ${ }^{5}$. Three types of papillae namely circumvallate, fungiform and foliate present on different sites of the tongue. Developmentally anterior $2 / 3^{\text {rd }}$ of the tongue originates from the $1^{\text {st }}$ and $2^{\text {nd }}$ pharyngeal arches. This part gets its somatosensation from the mandibular division of the trigeminal nerve and taste sensation from the chorda tympani branch of the facial nerve. The greater superficial petrosal branch of this nerve innervates taste buds on the soft palate. The posterior $1 / 3 \mathrm{rd}$ of the tongue develops from the third pharyngeal arch; and derives both taste and somatosensation from the Glossopharyngeal nerve. It also innervates the upper part of epiglottis. Rest of epiglottis, esophageal area, tonsillar pillars and root of the tongue derive from the branches of vagus nerve ${ }^{6,7}$.

These three cranial nerves carry taste sensation to the medulla then to the thalamus and finally to the primary gustatory cortex which is responsible for taste sensation. It is mentioned here that there is a close relation between taste and smell sensation; and as such when this area receives signals from taste buds, it also receives information about the smell as well ${ }^{8}$. However, ultimately they can recognize the different forms of tastes include salty, acidic, sweet, bitter, and umami (protein).

\section{TASTE DISTURBANCE}

Taste may be disturbed in various conditions namely common cold, allergic rhinitis, injury to the chorda tympani nerve, Bell palsy, radiation therapy and many more. It causes a refractory to decrease in appetite leading to less food intake causing weight loss. Adenoid hypertrophy disturbs taste in relation with smell ${ }^{8}$. Zinc deficiency and many drugs like metronidazole, antibiotics and antifungal may affect taste ${ }^{9,10}$. Many surgeries such as tonsillectomy ${ }^{11}$, ${ }^{12}$, middle ear surgery ${ }^{13-15}$, direct laryngoscopy ${ }^{16}$, 
ISSN No:-2456-2165

uvulopalatopharyngoplasty ${ }^{17}$ may lead to taste disturbance. Appropriate history and physical examination are more than ever essential to diagnose the post-tonsillectomy taste disturbance.

This study was conducted in the Bangladesh Medical College Hospital from 20015 to 2018. 1000 adult patient underwent tonsillectomy, age ranged in between 20-40 years. Among them 39 patients developed taste disturbance after 1 month of operation. These patient kept under regular surveillance and monitoring for a period of 6 months.

\section{Effects of tonsillectomy on taste}

Tonsillectomy is one of the most common surgeries in otolaryngological practice all over the world. Although rare, taste dysfunction occurs in some patients. The possibilities are described differently in different literatures and documented ${ }^{2-4}$ :

- Injury to nerve: direct or indirect damage to the glossopharyngeal nerve $(\mathrm{GN})$ or its lingual branch (LBGN). The course of the LBGN to the muscle layer of the palatine tonsillar bed is variable. They usually travel between the superior and middle pharyngeal constrictor muscles, but at times may remain partially exposed or adherent to the tonsillar capsule. During dissection, this can lead to the injury of the lingual branch of the glossopharyngeal nerve $\mathrm{e}^{11,12}$

- Operation duration: it is observed that jeopardy of the microcirculation to the tongue by tongue blade of mouth gag due to prolong compression can lead damage to the taste buds

- Injury to tonsillar bed: injury or damage to the muscle layer of the tonsillar bed or capsule lead to fibrosis of the muscles during healing process that in turn results disorder of the LBGN.

\section{Objective:}

The study was aimed to find out the possible cause of taste disturbance in the post-tonsillectomy patients and obtain informed written consent prior to tonsillectomy.

\section{PATIENTS AND METHODS}

$>$ Study design:

- Study type:

- Study period:

- Study place:

Retrospective study

From 2015 to 2018. Hospital

- Study Sample number: 1000 patients

- Study population:

- Evaluation period: operation.

- Sampling type: Random sampling

- Diagnosis and questionaries' : Appropriate history and physical examination

$>$ Inclusion criteria:

- Patient complaining of post-operative taste disturbance.

- Patient not regaining taste sensation after 1 month of operation.

\section{Evaluation method:}

- Taste disturbance persisted up to 1 month post operatively- Transient taste disturbance

- Taste sensation regained within 6 month - Temporary taste disturbance

- Taste disturbance persisted after 6 month - permanent taste disturbance.

> Exclusion criteria:

- Age below 20 years

- Patient having history of rhinitis.

- Patient history of drug intake.

- Patient having history of diabetes mellitus.

$>$ Operation:

- Methods

$\checkmark$ Bipolar diathermy

$\checkmark$ Dissection method

- Operation time: 30 minutes average

\section{RESULTS}

\begin{tabular}{|c|c|c|}
\hline Age in years & Male (\%) & Female (\%) \\
\hline $20-30$ & $345(35 \%)$ & $230(23 \%)$ \\
$31-40$ & $265(27 \%)$ & $170(17 \%)$ \\
\hline
\end{tabular}

Table 1:- age and sex distribution (n 1000)

\begin{tabular}{|c|c|c|}
\hline Temporary taste disturbance (\%) & Number of patents & $\%$ \\
\hline $\begin{array}{c}\text { Male } \\
\text { Female }\end{array}$ & $\begin{array}{l}17 \\
22\end{array}$ & $\begin{array}{l}1.7 \\
2.2\end{array}$ \\
\hline
\end{tabular}

Table 2:- Taste disturbance post-tonsillectomy patients after 1 month (n 1000)

\begin{tabular}{|c|c|c|}
\hline Taste regained & No of patients & $\%$ \\
\hline Male & 05 & 13 \\
Female & 04 & 10 \\
\hline
\end{tabular}

Table 3:- Follow up after 3 month of operation (n 39) 
ISSN No:-2456-2165

\begin{tabular}{|c|c|c|}
\hline Taste regained & No of patients & $\%$ \\
\hline Male & 12 & 40 \\
Female & 18 & 60 \\
\hline
\end{tabular}

Table 4:- Follow up after 6 month of operation (n 30)

\section{DISCUSSION}

Taste disturbance is an uncommon complication following tonsillectomy. There are a few studies have been found regarding post-tonsillectomy taste disturbances till to date. This condition is so horrifying that may produce a long-term nutritional deficiency resulting weight loss and decrease quality of life $\mathrm{e}^{10,18}$.

In our study we found complaints of taste disturbance more common in 20-40 years of age and is slightly higher in female which corresponds to other study ${ }^{19}$.

In this study it was relevant to the fact that following tonsillectomy most of the patients develop taste disturbance but all patients except $3.9 \%$ regained their taste after 7 to 30 days. In most of the published literature and the systematic review, the finding is variable ${ }^{1}$. A few studies about taste disorder following tonsillectomy can be found in the literature...but most of the clinical trials report that taste disorders are a very rare complication or something that disappears quickly. If it is permanent, "That is something that can really lower one's quality of life." Indeed, most research describes post-tonsillectomy transient taste dysfunction persist for a few weeks and regained taste spontaneously after completion of healing ${ }^{19}$.

Post-tonsillectomy taste disturbance may result from surgical injury, tongue compression, inflammatory processes or side effects of local anesthetics, prolonged tongue depression from a mouth gag that's inserted during a tonsillectomy could bring greater potential for a taste disturbance complication especially in adults ${ }^{20}$. Adult tonsillectomy is a rather traumatic experience for some patients, and can produce considerable post-operative swelling as well as pain during swallowing and mastication $^{18}$.

The close anatomic relationship between the palatine tonsil and the lingual branch of the glossopharyngeal nerve makes the nerve vulnerable during tonsillectomy. Clamping, knotting or use of electrocautery at the lower pole of the tonsil to control hemorrhage can injure the nerve ${ }^{21}$ that can easily be avoided my meticulous dissection and judicious use of cautery. Tonsillectomies in adults often take longer duration, because the tonsil tissue tends to be more fibrosed and the operation becomes messier and bloody which lead to more fibrosis in the healing process. The procedure can injure LBGN that become unable to carry the taste to the higher centers leading taste disturbance. It is also observed that surgery takes a little longer duration where pressure of the mouth gag can lead to compromise the circulation to the taste buds of the tongue. This condition can easily be prevented by intermittent relaxation of the tongue blade aiming to the restoration of the circulation in the tongue tissue for the normal functioning of the taste buds ${ }^{21}$. In our study, operation time taken by all surgeons rating from trainee to an experienced surgeons was on average 30 minutes. Experienced surgeon took only 10 to 15 minutes in our hospital setting.

\section{CONCLUSION}

Taste disturbance after tonsillectomy is a rare complication but has a significant impact on quality of life of patients. Meticulous dissection, avoidance of injuring the lower pole of the tonsil and judicious use of electrocautery/bipolar diathermy can save the LBGN. It also reduce the time of operation for all-out safety of the patients.

\section{REFERENCES}

[1]. Soldatova L, Doty RL. Post-tonsillectomy taste dysfunction: Myth or reality? World J Otorhinolaryngol Head Neck Surg. 2018 Mar; 4(1): 77-83.

[2]. Uzun C, Adali MK, Karasalihoglu AR. Unusual complication of tonsillectomy: taste disturbance and the lingual branch of the glossopharyngeal nerve. J Laryngol Otol. 2003 Apr; 117(4):314-7.

[3]. Landis B.N., Lacroix J.S. Postoperative/posttraumatic gustatory dysfunction. Adv Otorhinolaryngol. 2006; 63:242-254.

[4]. Randall DA; Taste impairment following tonsillectomy and adenoidectomy: an unusual Complication; Ear Nose Throat J. 2010 Sep; 89(9):E15-8.

[5]. Shaikh FH, Son A. Physiology, Taste. Treasure Island (FL): Stat Pearls Publishing; Jan 2020

[6]. Hadley K, Orlandi RR, Fong KJ. Basic anatomy and physiology of olfaction and taste. Otolaryngol. Clin. North Am. 2004 Dec; 37(6):1115-26.

[7]. Lewis D., Dandy W.E. The course of the nerve fibers transmitting sensation of taste. Arch Surg. 1930; 21:249-288.

[8]. Arvidson K. Location and variation in number of taste buds in human fungiform papillae. Scand J Dent Res. 1979 Dec; 87(6):435-42.

[9]. Konstantinidis I, Triaridis S, Triaridis A, Petropoulos I, Karagiannidis K, Kontzoglou G. How do children with adenoid hypertrophy smell and taste? Clinical assessment of olfactory function pre- and postadenoidectomy. Int. J. Pediatr. Otorhinolaryngol. 2005 Oct; 69(10):1343-9.

[10]. Goins MR, Pitovski DZ; Post-tonsillectomy taste distortion: a significant complication. Laryngoscope. 2004 Jul; 114(7):1206-13. 
[11]. Windfuhr J.P., Schlöndorff G., Sesterhenn A.M., Kremer B. From the expert's office: localized neural lesions following tonsillectomy. Eur Arch Otorhinolaryngol. 2009; 266:1621-1640.

[12]. Tomita H., Ohtuka K. Taste disturbance after tonsillectomy. Acta Otolaryngol Suppl. 2002:164-172

[13]. Saito T., Manabe Y., Shibamori Y. Long-term followup results of electrogustometry and subjective taste disorder after middle ear surgery. Laryngoscope. 2001; 111:2064-2070.

[14]. Yanagisawa K., Bartoshuk L.M., Catalanotto F.A., Karrer T.A., Kveton J.F. Anesthesia of the chorda tympani nerve and taste phantoms. Physiol Behav. 1998;63:329-335

[15]. Catalanotto F.A., Bartoshuk L.M., Östrum K.M., Gent J.F., Fast K. Effects of anesthesia of the facial nerve on taste. Chem Senses. 1993; 18:461-470.

[16]. 17. Gaut A., Williams M. Lingual nerve injury during suspension microlaryngoscopy. Arch Otolaryngol Head Neck Surg. 2000;126:669-671

[17]. 18. Rombaux P., Hamoir M., Bertrand B., Aubert G., Liistro G., Rodenstein D. Postoperative pain and side effects after uvulopalatopharyngoplasty, laser-assisted uvulopalatoplasty, and radiofrequency tissue volume reduction in primary snoring. Laryngoscope. 2003; 113:2169-2173.

[18]. Arnhold-Schneider M., Bernemann D. Incidence of taste disorders following tonsillectomy. HNO. 1987;35:195-198

[19]. Ohtuka K(1), Tomita H, Yamauchi Y, Kitagoh H. Nihon Jibiinkoka, Gakkai Kaiho. ; Taste.disturbance after tonsillectomy; 1994 Jun;97(6):1079-88

[20]. Windfuhr JP(1), Sack F, Sesterhenn AM, Landis BN, Chen YS; Post-tonsillectomy taste disorders ; Eur ArchOtorhinolaryngology.2010Feb;267(2):289-93

[21]. Temporale H, Zub K, Zatonski T, Krecicki T. PostTonsillectomy Taste Disorders-Review of Literature. J Otol Rhinol 2013, 2:3

[22]. Petrozzello D. Post-Tonsillectomy Taste Disorders Rare but Present. ENT today; December 2, 2012

[23]. Senska G, Hail H, Pütter C, Dost P. Long-Term Results From Tonsillectomy in Adults Dtsch Arztebl Int. 2015 Dec; 112(50): 849-855. 